\title{
Modified tube cystotomy for management of obstructive urolithiasis in young male bovines: $A$ review of 9 cases
}

\begin{abstract}
Obstructive urolithiasis is majoritily a complaint of male calves with tube cystotomy as the advised treatment, however the tube blockage is one of the post surgical complaints. This complication is reduced when modified technique of single stab incision is used for insertion of tube in abdominal cavity. The present study was conducted on 9 male bovine calves (8-Cattle and 1-Buffalo) presented with history of anuria and anorexia. Trans-abdominal B-mode ultrasonograhic examination with 3.5-5.0MHz transducer was adequate to visualize the urinary bladder in all calves. The urinary bladder was intact in 2 calves whereas in remaining 7 calves urine was present in the peritoneal cavity either due to complete $(n=6)$ or subserous $(n=1)$ rupture of the urinary bladder. Modified tube cystotomy followed by oral feeding of ammonium chloride $5 \mathrm{gm}$ total dose daily up to 10 days is practical and field applicable method for treatment of obstructive urolithiasis in male bovine calves.
\end{abstract}

Keywords: ammonium chloride, bovine, male, modified tube cystotomy, urolithiasis
Volume 7 Issue 3 - 2018

\author{
Prajwalita T Sutaria, JB Patel, AM Patel, PB \\ Patel, BN Suthar \\ Department of Veterinary Surgery \& Radiology, \\ Sardarkrushinagar Dantiwada Agricultural University, India
}

\begin{abstract}
Correspondence: Prajwalita T Sutaria, Department of Veterinary Surgery, Dr.VM Jhala Clinical Complex, College of Veterinary Science and Animal Husbandry, Sardarkrushinagar Dantiwada Agricultural University (SDAU), Deesa-385535
\end{abstract} Gujarat, India,Tel 09377899576,Email drprajwalita@gmail.com

Received: May 18, 2018 | Published: June 14, 2018

\section{Introduction}

Bovine male calves are given minimal care during their initial growing period. Urolithiasis is one of the commonly encountered affection in male bovines probably due to narrow, long and tortuous urethra with presence of sigmoid flexure. ${ }^{1}$ This combined with the less attention given to male bovines, tends the cases of anuria to go unnoticed leading to cystorrhexis, thus requiring emergency cystorrhaphy. The report of large number of urolithiasis cases in a particular breed or saline region may also hint towards a hereditary or demographic predisposition. In bovine calves the calculi are sandy in nature, mixed with blood and other tissue debris, ${ }^{2}$ at times filling the entire urethra, thus reducing the success of manual removal through urethrotomy and making chemical dissolution of such calculi through $\mathrm{pH}$ modulator along with tube cystotomy more practical. ${ }^{3,4}$ Hence, the present study was undertaken to evaluate the health status of male bovine calves with obstructive urolithiasis and its treatment using tube cystotomy followed by oral feeding of urinary acidifier ammonium chloride for dissolution of calculi.

\section{Materials and methods}

The present study was conducted on 9 male bovine calves (8-Cattle and 1-Buffalo) presented with history of anuria and anorexia. Detailed anamnesis regarding age, sex, duration of anorexia, abdominal distension and colic were noted in all calves under study. The heart rate (beats/minute), respiration rate (breaths/minute) and temperature $\left({ }^{\circ} \mathrm{F}\right)$ were observed using standard techniques. The color of conjunctival mucus membrane was and degree of dehydration was assessed by skin tent test. ${ }^{5}$ Abdominal ballottement was performed by grasping the ventral abdomen and percussing with finger tip for the presence or absence of fluid thrill. Abdominal paracentesis was performed using sterile $18 \mathrm{G}$ needle at paramedian site on either side of glans penis in standing animals. Ultrasonographic examination using $3.5-5 \mathrm{MHz}$ convex transducer in real time B-mode was conducted by placing the animal in dorsal recumbency with the transducer just anterior to pubis in both transverse and longitudinal planes. Jugular venous blood was collected before surgical intervention and on $12^{\text {th }}$ post-operative day to estimate the blood urea nitrogen and creatinine from serum using standard kits (Beacon, India). For modified tube cystotomy, in eight animals caudal paramedian laparotomy was conducted, while in one case with ruptured urethra the intact bladder was approached through left caudal flank laparotomy under linear infiltration with 2 per cent lignocaine hydrochloride. The ruptured urinary bladder was carefully exteriorized and examined for presence of any calculi. A 18 no Foley's catheter was passed into the abdominal cavity through a separate single stab incision approximately $5 \mathrm{~cm}$ lateral to the laparotomy incision site (Figure 1). The Foley's catheter was then passed into the urinary bladder through a stab incision and retained inside the bladder by inflating the bulb with $3 \mathrm{ml}$ normal saline and by placing a purse string suture on the bladder around the point of insertion (Figure 2). Cystorrhaphy was performed ( 7 cases) using chromic catgut 2-0 in single layer Cushing suture pattern. The laparotomy incision was closed in routine manner and the Foley's catheter was fixed on ventral abdominal skin using interrupted sutures with silk no 2 (Figure 3). Routine postoperative antibiotic, anti-inflammatory and fluid therapy was followed. In addition, feeding of ammonium chloride $5 \mathrm{gm}$ total dose daily up to 10 days was carried out. The sutures were removed in all calves on $12^{\text {th }}$ post-operative day. The Foley's catheter was removed after deflating the bulb and pulling it out from abdomen on resumption of normal urination. 


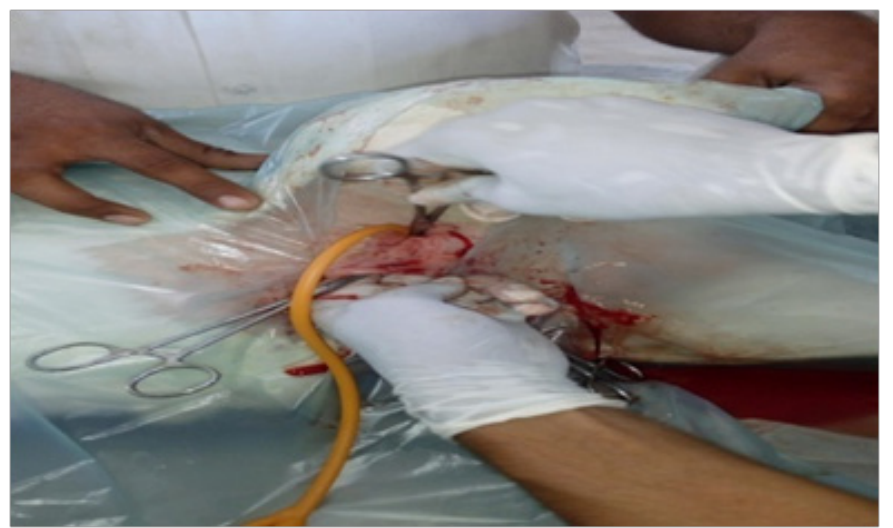

Figure I Single stab incision for Foleys catheter Placement.

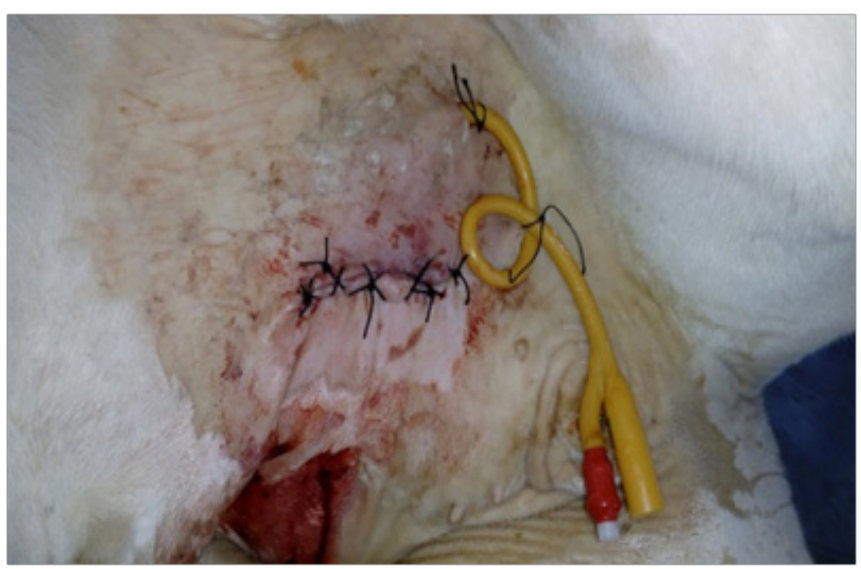

Figure 3 Modified tube cystotomy using 18 number Foley's catheter.

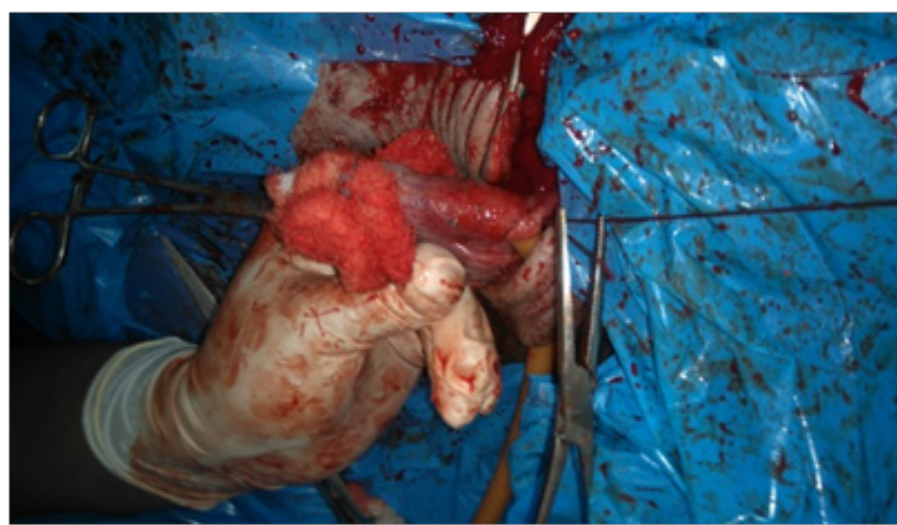

Figure 2 Insertion of Foleys catheter in urinary Bladder.

\section{Results and discussion}

The study was conducted on one Mehsana Buffalo and eight Kankrej cattle male calves presented with history of retention of urine. Obstructive urolithiasis is primarily a disease of young male bovines ${ }^{1}$ due to long, narrow and tortuous urinary tract as reflected in our study. Majority (77. $8 \%$ ) of calves (7/9) were under three months of age. In concurrence with our findings Kushwaha et al., ${ }^{3}$ and Khurma et al., ${ }^{4}$ have reported higher incidence of obstructive urolithiasis in bovines of 3-10 months of age. The detailed clinical observations viz. anuria, colic, anorexia, abdominal distension and varying degree of dehydration were taken and are dipicted in Table1. Urination was absent in all the calves, furthermore maximum (88.9 \%) number of calves (8/9) were anuric for 1-4 days except one which showed anuria for eight days prior to presentation. Colic was not observed in 3 calves at all, however, it was present before 3 days in two calves and before 2 days in 4 calves. Stoppage of urine due to blockage causes urinary bladder distension leading to abdominal pain manifested by kicking at belly and frequent rising and sitting down. ${ }^{3}$

Table I Health status of male bovine calves with urolithiasis

\begin{tabular}{|c|c|c|c|c|c|c|c|c|c|c|c|c|c|c|c|}
\hline $\begin{array}{l}\text { S } \\
\text { No. }\end{array}$ & $\begin{array}{l}\text { Case } \\
\text { No. }\end{array}$ & Village & Species & Sex & Breed & $\begin{array}{l}\text { Age } \\
\text { (months) }\end{array}$ & $\begin{array}{l}\text { History } \\
\text { of } \\
\text { anuria } \\
\text { (days) }\end{array}$ & $\begin{array}{l}\text { Feeding } \\
\text { absent } \\
\text { since } \\
\text { days }\end{array}$ & $\begin{array}{l}\text { Abdominal } \\
\text { distensin } \\
\text { since } \\
\text { (days) }\end{array}$ & $\begin{array}{l}\text { History } \\
\text { of colic } \\
\text { before } \\
\text { (days) }\end{array}$ & Recumbency & $\begin{array}{l}\text { Degree of } \\
\text { dehydration }\end{array}$ & $\begin{array}{l}\text { Defecation } \\
\left(+I_{-}\right)\end{array}$ & $\begin{array}{l}\text { Eye mucus } \\
\text { membrane }\end{array}$ & $\begin{array}{l}\text { Status of } \\
\text { urinary } \\
\text { bladder }\end{array}$ \\
\hline 1 & $207 / 84$ & Mevada & Cattle & M & Kankrej & 1 & 8 & 3 & 4 & 3 & Yes & +++ & - & Congested & Cystorhhexis \\
\hline 2 & $482 / 188$ & Bhachi & Cattle & M & Kankrej & 2 & 4 & 2 & 2 & 3 & No & ++ & - & Congested & Cystorhhexis \\
\hline 3 & $438 / 1084$ & Bhatram & Cattle & M & Kankrej & 12 & 1 & - & 1 & 1 & No & + & Pellets & Pale pink & Cystorhhexis \\
\hline 4 & $510 / 1286$ & Malupur & Cattle & M & Kankrej & 3 & 1 & - & I & - & No & ++ & Pellets & Pale pink & Cystorhhexis \\
\hline 5 & $819 / 2196$ & Malupur & Cattle & M & Kankrej & 3 & 2 & - & I & 1 & No & ++ & - & Congested & Subserosal \\
\hline 6 & $210 / 72$ & Bhadath & Cattle & M & Kankrej & 2 & 4 & 2 & 2 & 2 & No & ++ & Pellets & Congested & Cystorhhexis \\
\hline 7 & $729 / 2127$ & Utwada & Buffalo & M & Mehsana & 2 & 4 & 4 & - & - & No & +++ & Normal & Pale pink & Intact \\
\hline 8 & 1943/607 & Dantiwada & Cattle & M & Kankrej & 14 & 3 & 2 & I & 2 & No & ++ & - & Congested & Cystorhhexis \\
\hline 9 & $147 / 510$ & Patan & Cattle & M & Kankrej & 3 & 4 & 3 & - & - & No & +++ & Normal & Pale pink & Intact \\
\hline
\end{tabular}

Degree of dehydration: $+=$ mild $4 \%$ (STT $\leq 2$ seconds), $++=$ moderate 6-8\% (STT $\leq 3$ seconds), $+++=$ severe $10-12 \%$ (STT tents indefinitely) 
In three calves intermittent feeding was present while, six were anorexic for more than 2 days. Anuric animals goes off feed and water probably due to renal colic initially, leading to dehydration which gets compounded with the farm practice of withholding water to prevent urinary bladder rupture. Defecation was normal in two, absent in 4 calves and pelleted faeces were voided by rest which might be due to reduced intestinal motility owing to peritonitis. Abdominal distension was present in seven calves with cystorrhexis leading to increased free fluid as evident on abdominal ballottement and paracentesis. Similar findings were reported by Parrah et al., ${ }^{2}$ Kushwaha et al., ${ }^{3}$ and Khurma et al. ${ }^{4}$ If the cases of anuria are not treated timely then urinary bladder ruptures and condition worsens 24 to 48 hours later as uremia sets in. ${ }^{5}$ Amongst all animals, only one was in lateral recumbency, which had the longest history of anuria ( 8 days). Rest all calves were in normal standing condition. Kushwaha et al. ${ }^{3}$ also reported the recumbent calf having long history of anuria. The dehydration was mild to moderate in most calves and severe in three cases, the varying degree of dehydration might be due to the duration of anuria.

The eye mucus membrane was pale to pale-pink in four and congested in five calves. Similar observations were noted by Parrah et al., ${ }^{2}$ and Tamilmahan et al., ${ }^{6}$ in urinary retention cases. The mean heart rate, respiration rate and temperature were found within normal physiological limit at the time of presentation and on $12^{\text {th }}$ day after surgery (Table 2). However Kushwaha et al., ${ }^{3}$ and Tamilmahan et al., ${ }^{6}$ observed tachycardia and tachypnoea with normal rectal temperature in buffalo calves with urolithiasis. Ultrasound is a non invasive diagnostic tool used for examination of urinary bladder, as small bladder cannot be detected by abdominal palpation or radiography. ${ }^{7}$ Trans-abdominal B-mode ultrasonograhic examinations with 3.5$5.0 \mathrm{MHz}$ transducer visualized the urinary bladder in all calves. In present study free fluid in abdomen and empty urinary bladder with floating abdominal organs (Figure 4), mainly intestine were observed in 6 calves with cystorrhexis, while in one calf subserosal urinary bladder rupture was observed, indicated by distended urinary bladder along with free fluid in abdomen. Similar findings were recorded in cases of urinary bladder rupture by Parrah et al. ${ }^{2}$ In two calves distended intact urinary bladder was imaged with dilated neck (Figure 5) having multiple hyper echoic foci without acoustic shadow which might be urinary sediments. Parrah et al., ${ }^{2}$ have reported hyperechoic foci in distended urinary bladder of calves suffering with obstructive urolithiasis.

Table 2 Physiobiochemical parameters of male bovine calves with urolithiasis (Mean \pm S.E)

\begin{tabular}{|c|c|c|}
\hline Parameters & Before operation ( 0 day) & $\begin{array}{l}12 \text { day after } \\
\text { surgery }\end{array}$ \\
\hline \multicolumn{3}{|c|}{ Physiological parameters } \\
\hline Temperature $\left({ }^{\circ} \mathrm{F}\right)$ & $100.7 \pm 0.14$ & $100.2 \pm 0.18$ \\
\hline Heart rate/min & $62.78 \pm 2.62$ & $58.6 \pm 1.17$ \\
\hline $\begin{array}{l}\text { Respiration rate } \\
\text { Breath/min }\end{array}$ & $22.67 \pm 1.15$ & $21.2 \pm 0.46$ \\
\hline \multicolumn{3}{|c|}{ BUN and creatinine values } \\
\hline BUN (mmol/L) & $47.4 \pm 2.45$ & $16.78 \pm 0.64$ \\
\hline Creatinine $(\mu \mathrm{mol} / \mathrm{L})$ & $397.92 \pm 30.14$ & $135.33 \pm 5.80$ \\
\hline
\end{tabular}

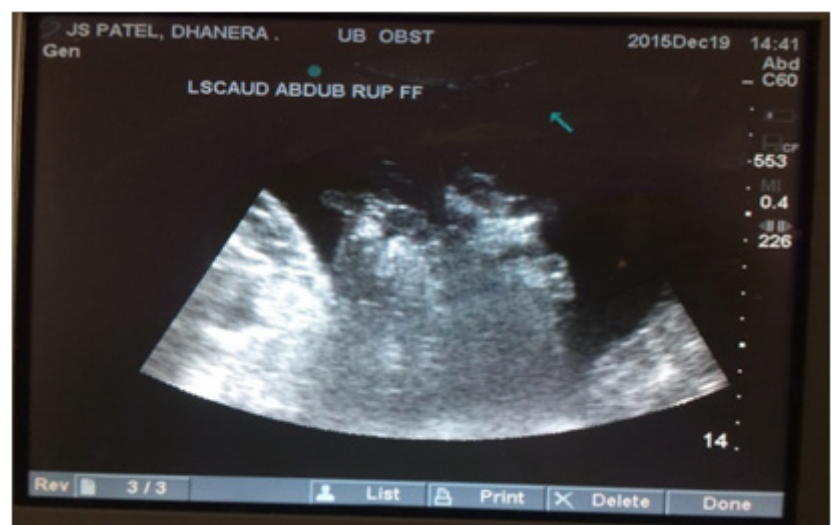

Figure 4 Real time B-mode ultrasonogram of caudal ventral abdomen showing free fluid in abdomen.

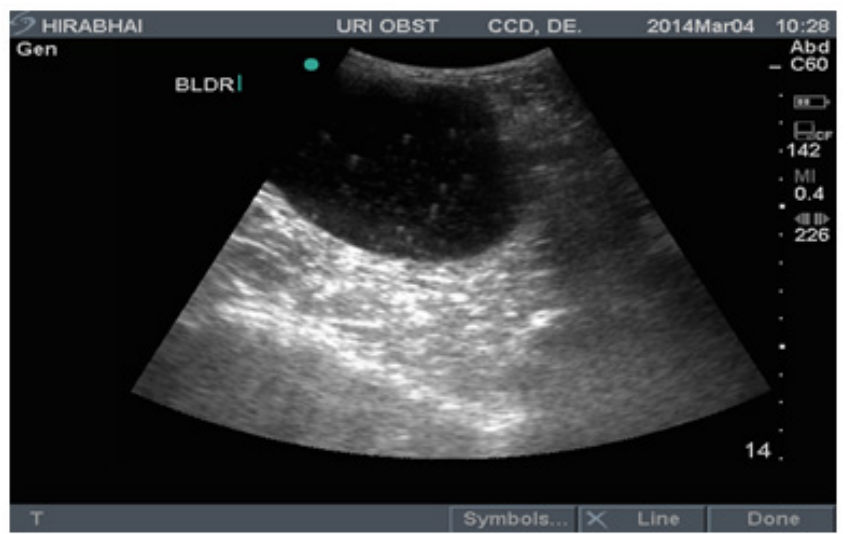

Figure 5 Real time B-mode ultrasonogram of caudal ventral abdomen showing distended urinary bladder having echogenic deposits.

The Serum blood urea nitrogen and creatinine revealed higher values (Table 2) than reference range prior to surgical intervention, which were near to normal reference range on $12^{\text {th }}$ post-operative day. The higher values were probably due to acute renal failure owing to back pressure of urine on kidneys and absorption from peritoneal cavity. ${ }^{2,8}$ Kerr $^{9}$ reported that variation in creatinine and blood urea levels could be used for early diagnosis and recovery from obstructive urolithiasis as observed in current study. Tube cystotomy along with calculolytic agent like ammonium chloride was proven effective for recovery from complete urinary obstruction without any postoperative complications in calves. For modified tube cystotomy, the caudal paramedian incision site was convenient to approach the bladder in eight calves. The 18 number Foley's catheter was inserted directly in the abdominal via a separate single stab incision at extreme paramedian site without creating a subcutaneous tunnel (Figure 1) thereby reducing the total operative time and the tissue damage. However, routine tube cystotomy as described by Parrah et al., ${ }^{2}$ Kushwaha et al., ${ }^{3}$ Tamilmahan et al. ${ }^{6}$ and Khurma et al., ${ }^{4}$ involves creating a subcutaneous tunnel for the foleys catheter fixation prior to its introduction in abdominal cavity. The subcutaneous tunnel is probably created to provide anchorage to the Foleys catheter to prevent its accidental dislodgement. In the calf having urethral rupture and subcutaneous urine infiltration a caudal left flank incision was used to approach the urinary bladder and the Foley's catheter was 
passed through separate stab incision at lower left caudal flank (Figure 6). Ammonium chloride is a urinary acidifier and along with tube cystotomy has a synergistic effect for quick recovery as suggested by Kushwaha et al., ${ }^{3}$ Parrah et al., ${ }^{2}$ and Tamilmahan et al. ${ }^{6}$ Complication of tube cystotomy like blockade of tube with blood or tissue debris, urethral rupture, tube dislodgement and infection have been reported by different authors. ${ }^{2,6}$ These complications were not observed in any of the calves under study, probably as the Foleys catheter was directly inserted in the abdominal cavity by single stab incision without making any subcutaneous tunnel. This prevented excessive bending of catheter thus avoiding above complications. The normal urination was resumed in 5 calves on 10-12 postoperative days and in 4 calves after 15 days of surgery with removal of Foley's catheter.

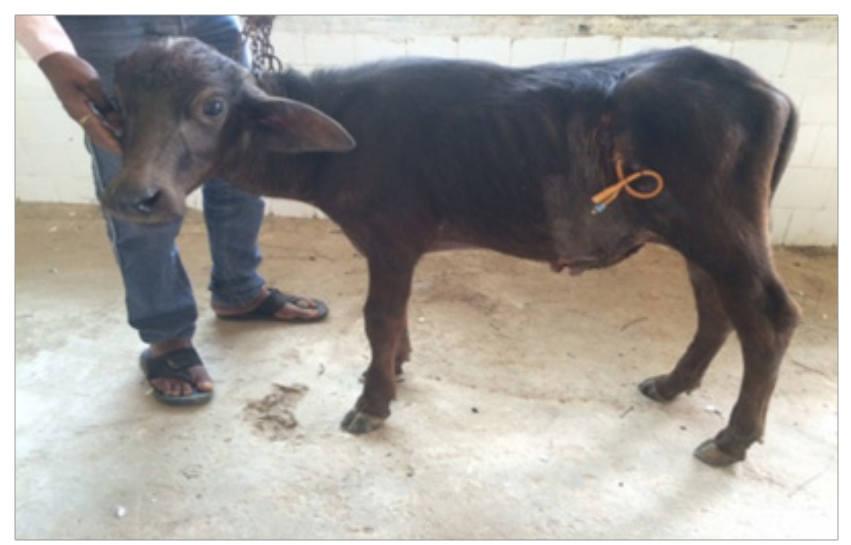

Figure 6 Post operative buffalo calf with tube cystotomy in left caudal flank.

\section{Conclusion}

Modified tube cystotomy followed by oral feeding of ammonium chloride $5 \mathrm{gm}$ total dose daily up to 10 days is practical and field applicable method for treatment of obstructive urolithiasis in male bovine calves.

\section{Acknowledgement}

We are thankful to the Dean, College of Veterinary Science for providing the facilities for research.

\section{Conflicts of interest}

Author declares there is no conflict of interest.

\section{References}

1. Sharma AK, Mogha IV, Singh GR. Incidence of urethral obstruction in animals. Indian J Anim. Sci. 2007;77:455-456.

2. Parrah JD, Moulvi BA, Hussain SS, et al. Innovative tube cystostomy for the management of bovine clinical cases of obstructive urolithiasis. Vet Arhiv. 2011;81(3):321-337.

3. Kushwaha RB, Amarpal Aithal HP, Kinjavdekar P, et al. Clinical appraisal of 48 cases of obstructive urolithiasis in buffalo calves treated with tube cystostomy and urethrotomy. Adv Anim Vet Sci. 2014;2(2):106-110.

4. Khurrma J, Choudhary CR, Sharma V, et al. Tube cystostomy for management of obstructive urolithiasis in buffalo calves. International Journal of Science, Environment and Technology. 2017;6(1):413-419.

5. Radostits OM, Blood DC, Gay CC, et al. Veterinary Medicine: A textbook of the diseases of cattle, sheep, pigs, goats and horse. $9^{\text {th }}$ edn. ELBS Bailliere Tindall: London: 2000. p. 1877.

6. Tamilmahan P, Mohsina A, Karthik K, et al. Tube cystostomy for management of obstructive urolithiasis in ruminants. Veterinary World. 2014;7(4):234-239.

7. Biller DS, Kantrowitz B, Partington BP. Diagnostic ultrasound of the urinary bladder. J Am Anim Hosp Assoc. 1990;26:397-402.

8. Sharma PD, Singh K, Singh J. Bacteriological, biochemical and histopathological studies in uroperitoneum in buffalo calves (Bubalus bubalis). Indian J Anim Sci. 2006;76:124-126.

9. Kerr MG. Veterinary Laboratory Medicine Clinical Biochemistry and Haematology. Blackwell Science Ltd; 2002. 